\title{
Treatment for Tobacco Dependence: Effect on Brain Nicotinic Acetylcholine Receptor Density
}

\author{
Arthur L Brody*, I,2 Alexey G Mukhin ${ }^{3}$, Stephanie Shulenberger², Michael S Mamoun ${ }^{2}$, Maggie Kozman², \\ Jonathan Phuong ${ }^{2}$, Meaghan Neary², Trinh Luu ${ }^{2}$ and Mark A Mandelkern ${ }^{2,4}$ \\ 'Department of Psychiatry and Biobehavioral Sciences, University of California, Los Angeles, CA, USA; ${ }^{2}$ Department of Research, VA Greater Los \\ Angeles Healthcare System, Los Angeles, CA, USA; ${ }^{3}$ Department of Psychiatry, Duke University, Durham, NC, USA; ${ }^{4}$ Department of Physics, \\ University of California, Irvine, CA, USA
}

\begin{abstract}
Cigarette smoking leads to upregulation of brain nicotinic acetylcholine receptors (nAChRs), including the common $\alpha_{4} \beta_{2} * \mathrm{nAChR}$ subtype. Although a substantial percentage of smokers receive treatment for tobacco dependence with counseling and/or medication, the effect of a standard course of these treatments on nAChR upregulation has not yet been reported. In the present study, 48 otherwise healthy smokers underwent positron emission tomography (PET) scanning with the radiotracer 2-FA (for labeling $\alpha_{4} \beta_{2}{ }^{*}$ $\mathrm{nAChRs)} \mathrm{before} \mathrm{and} \mathrm{after} \mathrm{treatment} \mathrm{with} \mathrm{either} \mathrm{cognitive-behavioral} \mathrm{therapy,} \mathrm{bupropion} \mathrm{HCl}$, or pill placebo. Specific binding volume of distribution $\left(V_{S} / f_{P}\right)$, a measure proportional to $\alpha_{4} \beta_{2}{ }^{*} \mathrm{nAChR}$ density, was determined for regions known to have $\mathrm{nAChR}$ upregulation with smoking (prefrontal cortex, brainstem, and cerebellum). In the overall study sample, significant decreases in $V_{S} / f_{P}$ were found for the prefrontal cortex, brainstem, and cerebellum of $-20( \pm 35),-25( \pm 36)$, and $-25( \pm 31) \%$, respectively, which represented movement of $V_{S} / f_{P}$ values toward values found in non-smokers (mean $58.2 \%$ normalization of receptor levels). Participants who quit smoking had significantly greater reductions in $V_{S} / f_{P}$ across regions than non-quitters, and correlations were found between reductions in cigarettes per day and decreases in $V_{S} / f_{P}$ for brainstem and cerebellum, but there was no between-group effect of treatment type. Thus, smoking reduction and cessation with commonly used treatments (and pill placebo) lead to decreased $\alpha_{4} \beta_{2} * \mathrm{nAChR}$ densities across brain regions. Study findings could prove useful in the treatment of smokers by providing encouragement with the knowledge that decreased smoking leads to normalization of specific brain receptors.

Neuropsychopharmacology (2013) 38, 1548-1556; doi:I0.1038/npp.2013.53; published online 20 March 2013
\end{abstract}

Keywords: tobacco dependence; nicotine; nicotinic acetylcholine receptor; bupropion; cognitive-behavioral therapy; positron emission tomography

\section{INTRODUCTION}

In the United States, roughly $19 \%$ of adults ( $\sim 46$ million) smoke cigarettes (CDC, 2009). The majority of these smokers $(62.7 \%)$ are screened for tobacco dependence when visiting a physician, and a substantial percentage receives either counseling $(20.9 \%)$ or medication $(7.6 \%)$ to aid in smoking cessation (Jamal et al, 2012). Current firstline treatments for smoking include counseling with cognitive-behavioral therapy (CBT) and bupropion $\mathrm{HCl}$ (Zyban), as well as nicotine replacement therapies (such as the patch, gum, and lozenge) and varenicline (Chantix) (Fant et al, 2009; Jamal et al, 2012). Although the efficacy of these treatments is extensively documented (Agboola et al, 2010; Cahill et al, 2011), changes in brain nicotinic

*Correspondence: Dr AL Brody, Department of Psychiatry and Biobehavioral Sciences, University of California, 300 UCLA Medical Plaza, Suite 2200, Los Angeles, CA 90095, USA,

Tel: + I 310268 4778, Fax: + I 3102062802 ,

E-mail: abrody@ucla.edu

Received 12 December 2012; revised 10 February 2013; accepted 12 February 2013; accepted article preview online 21 February 2013 acetylcholine receptors (nAChRs) with a standard course of these treatments have not yet been reported.

Cigarette smoking leads to upregulation of nAChRs in the human brain, including the common $\alpha_{4} \beta_{2}{ }^{*}$ nAChR subtype (Whiting and Lindstrom, 1988). Human postmortem tissue studies show that chronic smokers have increased numbers of $\alpha_{4} \beta_{2}{ }^{*}$ nAChRs compared with non-smokers (Benwell et al, 1988; Breese et al, 1997) and that former smokers ( $>1$ year abstinent) have nAChR densities similar to nonsmokers (Breese et al, 1997). Many laboratory animal studies also demonstrate upregulation of nAChRs in response to chronic nicotine administration (eg, Marks et al, 2011; Zhang et al, 2002).

The functional significance of $\mathrm{nAChR}$ upregulation has been extensively studied (Govind et al, 2009; Lester et al, 2009; Quick and Lester, 2002), and although the exact significance of this upregulation is not fully known, laboratory studies indicate that nicotine exposure leads to increased receptor function and sensitivity to nicotine. Increased receptor number and function may be due to nicotine administration resulting in increased trafficking of nAChRs to the cell surface, increased receptor assembly 
and/or maturation, or other mechanisms (Govind et al, 2009).

Previous brain imaging studies of human smokers, including a recent one by our group, have used positron emission tomography (PET) or single photon emission computed tomography to demonstrate upregulation of nAChRs in smokers compared with non-smoking controls in brain regions other than the thalamus (Brody et al, 2013; Cosgrove et al, 2009; Mamede et al, 2007; Mukhin et al, 2008; Staley et al, 2006; Wullner et al, 2008). In follow-up scanning, nAChR upregulation in smokers was found to normalize to levels of non-smokers when participants were given contingency management to maintain abstinence for roughly 3 (Mamede et al, 2007) to 12 (Cosgrove et al, 2009) weeks. However, to our knowledge, no one has yet reported the effects of commonly used, standard first-line treatments for cigarette smoking on nAChR density.

Another aspect of commonly used treatments that has not yet (to our knowledge) been studied with brain imaging is prediction of treatment response. The most replicated predictor of smoking cessation outcome is severity of dependence on cigarettes, which includes number of cigarettes per day (Batra et al, 2008; Dale et al, 2001; Hymowitz et al, 1997; Japuntich et al, 2011; Kozlowski et al, 1994; Paluck et al, 2006; Westman et al, 1997). Greater severity of dependence has been associated with poorer outcome for group psychotherapy (Kozlowski et al, 1994), bupropion $\mathrm{HCl}$ (Dale et al, 2001; Paluck et al, 2006), and nicotine patch (Batra et al, 2008; Westman et al, 1997), as well as in naturalistic settings with no specific treatment (Hymowitz et al, 1997). Other factors, such as self-efficacy/ self-confidence (Gwaltney et al, 2005; Haaga and Stewart, 1992; Li and Froelicher, 2008; Schnoll et al, 2003; Shiffman et al, 2000), desire to quit (Wiggers et al, 2005), low negative affect (Shiffman et al, 2007), absence of depression (Japuntich et al, 2007), little craving response to cues (Waters et al, 2004), low anger (Al'Absi et al., 2007), slow nicotine metabolism (Schnoll et al, 2009), and absence of lapses during early treatment (Kenford et al, 1994) have also been found to predict quit status. Thus, clinical factors have been extensively studied for their value in predicting treatment response, with greater severity of specific symptoms being linked to less likelihood of quitting.

In the present examination of a relatively large sample of PET scans from smokers, we sought to: (1) determine the effects of first-line treatments for cigarette smoking (group CBT and bupropion $\mathrm{HCl}$ ) on $\alpha_{4} \beta_{2}{ }^{*} \mathrm{nAChR}$ density, with the primary study hypothesis being that movement toward normalization of $\alpha_{4} \beta_{2}{ }^{*} \mathrm{nAChR}$ densities occurs with decreased nicotine exposure from smoking from before to after treatment, (2) explore associations between reduced nAChR density with treatment and smoking-related symptoms, and (3) explore whether pre-treatment nAChR levels predict response to these treatments.

\section{MATERIALS AND METHODS}

\section{Participants and Screening Methods}

Forty-eight otherwise healthy adult smokers underwent PET scanning before and after treatment. Participants were recruited using the same methodology as in our previous reports (Brody et al, 2011; Brody et al, 2013). The central inclusion criteria were current nicotine dependence and smoking 10-40 cigarettes per day. Exclusion criteria were pregnancy, use of a medication or history of a medical condition that might affect the central nervous system at the time of scanning, or any history of mental illness or substance abuse/dependence. In addition to the 48 participants with full data sets, 14 participants enrolled in the study and underwent pre-treatment PET scanning, but their data were used only for the examination of prediction of treatment response either because they did not complete treatment $(n=12)$ or because they did not have a usable second PET scan due to scanner malfunction $(n=2)$. Thus, 110 PET scans were used for the data analysis.

During an initial visit, screening data were obtained to verify participant reports and characterize smoking history. Rating scales were the Smoker's Profile Form (containing demographic variables and a detailed smoking history), Fagerström Test for Nicotine Dependence (FTND) (Heatherton et al, 1991), Hamilton Depression Rating Scale (Hamilton, 1967), Hamilton Anxiety Rating Scale (Hamilton, 1969), and Beck Depression Inventory (Beck and Steer, 1996). An exhaled carbon monoxide (CO) level was determined using a MicroSmokerlyzer (Bedfont Scientific, Kent, UK) to verify smoking status ( $\mathrm{CO} \geqslant 8$ parts per million $(\mathrm{ppm})$ ). A breathalyzer (AlcoMatePro) test, urine toxicology screen (Test Country I-Cup Urine Toxicology Kit), and urine pregnancy test (for women of childbearing potential; Test Country Cassette Urine Pregnancy Test) were obtained to support the participant's report of no current alcohol or drug dependence and no pregnancy. This study was approved by the local Institutional Review Board (IRB) and Radiation Safety Committee, and participants provided written informed consent.

\section{Abstinence Period and PET Protocol}

Approximately 1 week after the initial screening session, participants underwent PET scanning with the same general abstinence and 2-FA bolus-plus-continuous-infusion PET protocol as in previous studies (Brody et al, 2009; Brody et al, 2011; Brody et al, 2013). Participants began smoking/ nicotine abstinence two nights before the pre- and posttreatment PET sessions and were monitored as described previously, so that nicotine from smoking would not compete with the radiotracer for receptor binding during scanning. On the day of PET scanning, participants arrived at the PET center at 1100 hours, reported on their abstinence, and had an exhaled CO measurement (a level of $\leqslant 4 \mathrm{ppm}$ was considered as consistent with smoking abstinence). At 1200 hours, bolus-plus-continuous-infusion of 2-FA was initiated, with $147 \mathrm{MBq}$ of 2-FA administered as an intravenous bolus in $5 \mathrm{ml}$ saline over $10 \mathrm{~s}$. This same amount of 2-FA was also diluted in $60 \mathrm{ml}$ saline, and $51.1 \mathrm{ml}$ was infused over the next $420 \mathrm{~min}(7.3 \mathrm{ml} / \mathrm{h})$ by a computercontrolled pump (Harvard model 22, Harvard Instruments, Natick, MA). After initiation of the bolus-plus-continuousinfusion, participants remained seated for the next $4 \mathrm{~h}$ to allow the radiotracer to reach a relatively steady state in brain. At 1600 hours, PET scanning commenced and continued for $3 \mathrm{~h}$, with a 10 -min break after 90 -min of scanning. Scans were acquired as a series of 10-min frames. 
PET scans were obtained using the Philips Gemini TruFlight (Koninklijke Philips Electronics N.V., Eindhoven, the Netherlands), a fully three-dimensional PET-CT scanner, which was operated in non-TOF mode. Reconstruction was done using Fourier rebinning and filtered back projection, and scatter and random corrections were applied. The mean spatial resolution (FWHM) for brain scanning is $5.0 \mathrm{~mm}$ (transverse) by $4.8 \mathrm{~mm}$ (axial). 2-FA was prepared using a published method (Dolle et al, 1998). A magnetic resonance imaging (MRI) scan of the brain was obtained for each participant within a week of PET scanning with the same specifications as in our previous report (Brody et al, 2011). Blood samples were drawn during PET scanning for determinations of free, unmetabolized 2-FA and nicotine plasma levels, as described previously (Brody et al, 2013).

\section{Symptom Rating Scale Administration}

In addition to baseline ratings cited above, symptom rating scales were obtained at the beginning and end of treatment and at both PET scanning sessions. Before and after the treatment, participants were asked to rate on an analog scale how rewarding a cigarette would be and how a cigarette would taste $(0=$ none/bad to $10=$ very much/great $)$. During the PET sessions, the Urge to Smoke (UTS) (Jarvik et al, 2000) craving scale (an analog scale with 10 craving-related questions rated on a scale of 0-6), Profile of Mood States (POMS) (McNair et al, 1988), and Shiffman-Jarvik Withdrawal Scale (SJWS) (Shiffman and Jarvik, 1976) were administered.

\section{Treatment for Tobacco Dependence}

Within a week of the initial PET session, participants were randomly assigned to treatment with $\mathrm{CBT}$, bupropion $\mathrm{HCl}$ sustained release formula, or matching pill placebo. These treatments were continued through the second PET scanning session at 11 weeks, with all the participants instructed to have a target quit date of 2 weeks after initiating treatment. Participants receiving pill treatments did not receive concomitant psychotherapy, in order to isolate the effects of the treatment types.

Participants randomized to CBT had weekly 60-min group psychotherapy sessions, using standard clinical techniques (Abrams et al, 2003). Psychotherapy consisted of education about smoking addiction, withdrawal, and relapse prevention; recognizing danger situations (triggers) that could lead to relapse; developing new coping skills, such as avoiding triggers, coping with negative affective states, reducing overall stress, and distracting attention from smoking using thought-stopping techniques; developing lifestyle changes; and social support (Carmody, 1990; Fiore et al, 2000). Participants had exhaled CO levels monitored at each session and were encouraged to taper off cigarettes. The manualized psychotherapy sessions were performed on a rotating basis by a study psychotherapist (SS) and the PI.

Participants randomized to receive bupropion $\mathrm{HCl}$ or matching pill placebo were treated in a double-blind manner. A research pharmacist distributed packets of medication/placebo to a study physician (ALB or MSM). These packets were identified by a numeric code recorded by the pharmacist. Film-coated bupropion $\mathrm{HCl}$ SR and placebo were obtained from the Biomedical Research Institute of New Mexico (Albuquerque, NM). Placebo ingredients were inert and the same as those found in bupropion $\mathrm{HCl}$ SR tablets. Participants were started on 1 pill per day (150 mg pills for bupropion) on the day following the first PET scanning session for 3 days, with the dosage increased to 1 pill orally twice per day thereafter. All participants receiving pill treatment were advised of potential benefits and side effects of bupropion $\mathrm{HCl}$ when given their study medication/placebo and met with a study physician weekly for medication management visits (15 min). During these visits, titration of dosage, review of side effects, and monitoring of cigarette usage took place, as well as the measurement of exhaled CO. Participants in the bupropion $\mathrm{HCl}$ and placebo groups were instructed to take the twice daily dosing through the second PET session.

For all the participants, quit status was defined as a selfreport of $\geqslant 7$ days of continuous abstinence from smoking and an exhaled CO level of $\leqslant 8 \mathrm{ppm}$ at the time of the follow-up PET session.

\section{PET Image Analysis}

After decay and motion correction, each participant's PET scan(s) were co-registered to their MRI using PMOD version 2.9 (http://www.pmod.com/technologies/). Regions of interest (ROIs) were drawn on MRI using PMOD and transferred to the co-registered PET. ROIs were the prefrontal cortex, brainstem, and cerebellum, which were chosen for three reasons. First and most importantly, previous reports indicate that these ROIs (and most brain regions other than the thalamus) have upregulation of nAChR densities in cigarette smokers (Brody et al, 2013; Mamede et al, 2007; Mukhin et al, 2008; Staley et al, 2006; Wullner et al, 2008). Second, these ROIs have a range of 2-FA-binding levels from moderate to high (Brody et al, 2006; Brody et al, 2013; Kimes et al, 2008; Mukhin et al, 2008), which eliminates the issues of examining the highest nAChR density region (thalamus) as an experimental variable (because it does not have upregulation of nAChRs in smokers), and ROIs with very low nAChR density (eg, corpus callosum), which may have very small differences between groups or conditions. And third, the use of a limited number of regions maintained power for the central statistical analysis of the study, which includes a correction for number of ROIs studied. Representative slices of the prefrontal cortex (middle frontal gyrus) were drawn bilaterally, while the brainstem and cerebellum were drawn as whole structures. ROI placement was visually inspected for each PET frame in order to minimize the effects of coregistration errors and movement; this procedure was repeated if there was a noticeable problem.

Specific binding volume of distribution (designated as $\mathrm{V}_{\mathrm{S}}$ / $f_{P}$, based on standard nomenclature (Innis et al, 2007)) was calculated for each region and used for the central study analyses, because this value is proportional to $\alpha_{4} \beta_{2}{ }^{*} \mathrm{nAChR}$ density. $V_{\mathrm{S}} / \mathrm{f}_{\mathrm{P}}$ values were determined for each participant as the difference between total binding volume of distribution $\left(\mathrm{V}_{\mathrm{T}} / \mathrm{f}_{\mathrm{P}}\right)$ and the nondisplaceable volume of distribution corrected for the free fraction of plasma 2-FA $\left(\mathrm{V}_{\mathrm{ND}} / \mathrm{f}_{\mathrm{P}}\right)$, such that $\mathrm{V}_{\mathrm{S}} / \mathrm{f}_{\mathrm{P}}=\mathrm{V}_{\mathrm{T}} / \mathrm{f}_{\mathrm{P}}-\mathrm{V}_{\mathrm{ND}} / \mathrm{f}_{\mathrm{P}} \cdot \mathrm{V}_{\mathrm{T}} / \mathrm{f}_{\mathrm{P}}$ values were determined 
from the 17 10-min PET frames and is defined as the ratio $\mathrm{C}_{\mathrm{T}} /\left(\mathrm{C}_{\mathrm{P}} \cdot \mathrm{f}_{\mathrm{P}}\right)$, where $\mathrm{C}_{\mathrm{T}}$ is the mean total decay-corrected concentration of $2-F A$ in the ROIs, $\left(C_{P} \cdot f_{P}\right)$ is the mean decay-corrected concentration of free 2-FA in plasma, and $f_{P}$ is the fraction of free (unbound) 2-FA in plasma. $V_{N D} / f_{P}$ values were based on data from previously published findings by our group (Brody et al, 2011; Brody et al, 2006). In addition, for scans in which participants had a measurable plasma concentration of nicotine $(\geqslant 0.2 \mathrm{ng} / \mathrm{ml})$, $\mathrm{V}_{\mathrm{S}} / \mathrm{f}_{\mathrm{P}}$ values were corrected for nicotine levels at the time of scanning using the following equation: $V_{S} / f_{P}=\left(V_{S} / f_{P}\right)_{o b s} /$ $\left(1-\mathrm{I} / \mathrm{IC}_{50}\right)$, where $\left(\mathrm{V}_{\mathrm{S}} / \mathrm{f}_{\mathrm{P}}\right)_{\text {obs }}$ is the observed value of specific binding volume of distribution, I is the plasma nicotine level at the time of scanning, and $\mathrm{IC}_{50}$ is the plasma nicotine concentration resulting in $50 \%$ reduction in $\mathrm{V}_{\mathrm{S}} / \mathrm{f}_{\mathrm{P}}$. The $\mathrm{IC}_{50}$ value of $0.87 \mathrm{ng} / \mathrm{ml}$ used here was previously reported by our group (Brody et al, 2006).

\section{Statistical Analysis}

Means ( \pm SDs) were determined for demographic, rating scale, and smoking-related variables for the entire study sample and study subgroups based on treatment type. Baseline data were compared among subgroups using analyses of variance for continuous data and Chi-Square tests for categorical data to determine if groups were comparable on these items before treatment. For verifying the effect of treatment on smoking-related variables, repeated-measures analyses of covariance (ANCOVA) were performed, with the smoking-related variable (ie, cigarettes per day and exhaled CO levels) as the repeated measure, treatment type as a between-group variable, and age as a nuisance covariate (as the subgroups differed in age and previous research indicates that $\mathrm{nAChR}$ densities decline with age (Brody et al, 2013; Mitsis et al, 2007; Rogers et al, 1998)). All ANCOVA results are presented as GreenhouseGeisser corrected values.

For evaluating changes in $\alpha_{4} \beta_{2}{ }^{*} \mathrm{nAChR}$ density with treatment, an overall multivariate repeated-measures analysis of covariance (MANCOVA) was performed using $V_{S} / f_{P}$ values for the three ROIs pre- and post-treatment as repeated measures, treatment subgroup (CBT, bupropion, or placebo) and quit status as between-subject factors, and age as a nuisance covariate. This MANCOVA controls for Type 1 error for a multivariate-dependent variable, here $V_{S} / f_{P}$ values for the ROIs. Follow-up ANCOVAS were performed for each brain region separately with the same variables as for the overall MANCOVA. For examining associations between decreases in $V_{S} / f_{P}$ values and reductions in cigarettes per day, Pearson Product Moment Correlation coefficients were determined between these variables.

For exploratory analyses, Pearson Product Moment Correlation coefficients were determined between $V_{S} / f_{P}$ values and subjective symptom rating scales (analog cigarette taste and reward scales, UTS craving scale, SJWS, and POMS; uncorrected for multiple comparisons). For exploring pre-treatment predictors of treatment response, binary logistic regression was used, as in previous studies (Dale et al, 2001; Japuntich et al, 2011; Schnoll et al, 2003; Westman et al, 1997), with quit status as the dependent variable and pre-treatment smoking-related (cigarettes per day and cigarette-related rating scales) and $\mathrm{PET} \mathrm{V}_{\mathrm{S}} / \mathrm{f}_{\mathrm{P}}$ data as the covariates (uncorrected for multiple comparisons). For these exploratory analyses, data from participants who did not complete treatment or did not have a usable second scan were included and non-completers were considered to be non-quitters (in accordance with the recent recommendations (Hughes et al, 2003; West et al, 2005) and use (Rigotti et al, 2009) of this classification). Statistical tests were performed using PASW/SPSS Statistics version 19.0 (SPSS, Chicago, IL).

\section{RESULTS}

\section{Baseline Demographic and Rating Scale Data}

At baseline, the study sample was middle-aged (42.8 ( \pm 13.7$)$ years old), mostly male $(72.9 \%)$, and roughly half Caucasian (54.2\%), with some college education (14.5 $( \pm 1.9))$ and minimal anxiety/depressive symptoms

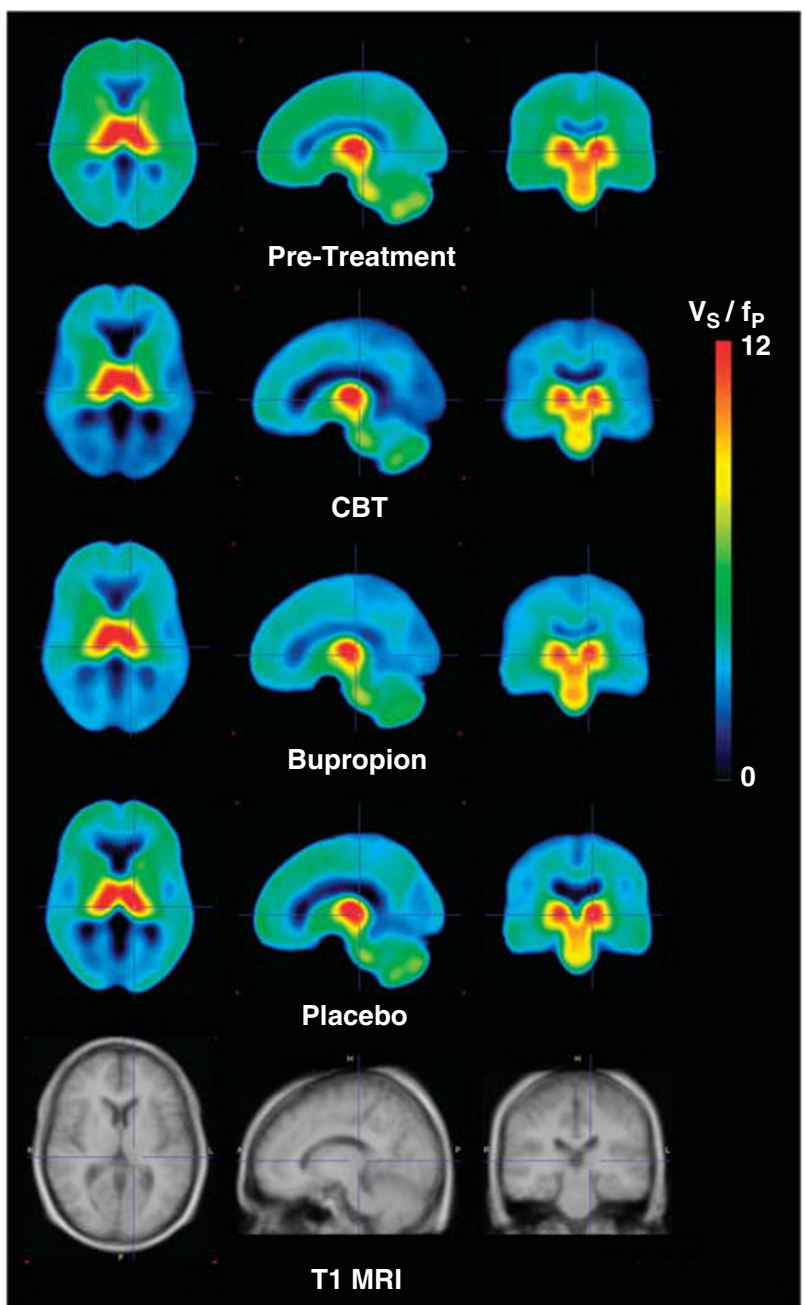

Figure I Mean positron emission tomography (PET) images from the study sample demonstrating decreased 2-FA binding from pre- to posttreatment for the three treatment groups. Top row consists of pretreatment scans $(n=48)$, followed by the post-treatment mean images for the cognitive-behavioral therapy (CBT; $n=16)$, bupropion $\mathrm{HCl}(n=18)$, and pill placebo $(n=14)$ treatment groups (rows $2-4$, respectively). Mean PET images were spatially normalized to a group mean magnetic resonance imaging (MRI) scan (bottom row). $V_{S} / f_{P}=$ specific binding volume of distribution. 
(Table 1). The sample smoked roughly one pack of cigarettes per day on average $(19.6( \pm 4.0))$ and was moderately nicotine-dependent (FTND $-4.2( \pm 2.3)$ ).

Study subgroups based on assigned treatment type did not differ on any demographic or rating scale scores other than age, which was higher for the CBT-treated subgroup $(51.6( \pm 12.3))$ than for the bupropion- $(35.5( \pm 11.6))$ or placebo- $(42.1( \pm 12.5))$ treated subgroups $(F(2,45)=7.5$, $P=0.002$ ). For this reason, age was used as a nuisance covariate in all between-group analyses.

\section{Effects of Treatment on Smoking-Related Variables}

As expected, treatment for tobacco dependence was associated with a decrease in number of cigarettes per day $(\mathrm{F}(1,44)=13.7, P=0.001)$, with the study sample having a $54( \pm 38) \%$ reduction. A significant interaction between time from pre- to post-treatment and subgroup based on treatment type was also found $(\mathrm{F}(2,44)=6.4, P=0.004)$, with the CBT-treated subgroup having a greater reduction in cigarettes per day $(-76( \pm 30)) \%$ than the bupropiontreated $(-38( \pm 35)) \%$ or placebo-treated $(-50( \pm 41)) \%$ subgroups. Treatment was also associated with decreased CO levels $(F(1,44)=5.4, P<0.05)$, with no significant between-group effect (Table 1). Eleven participants met criteria for having quit smoking at the end of treatment ( $n=7$ for CBT, 1 for bupropion, and 3 for placebo).

\section{Effects of Treatment on $\alpha_{4} \beta_{2}{ }^{*}$ nAChR density}

For the overall MANCOVA examining effects of treatment on $\alpha_{4} \beta_{2}{ }^{*}$ nAChR density, both changes in $\mathrm{V}_{\mathrm{S}} / \mathrm{f}_{\mathrm{P}}$ from pre- to post-treatment $(\mathrm{F}(1,41)=5.6, P=0.02)$ and differences between quitters and non-quitters $(\mathrm{F}(1,41)=5.8, P=0.02)$ were significant, with no significant effect of treatment type $(\mathrm{F}(2,41)=1.2, \mathrm{NS})$. In the overall study sample, treatment was associated with decreases in $V_{S} / f_{P}$ in the prefrontal cortex, brainstem, and cerebellum by $-20( \pm 35),-25$ $( \pm 36)$, and $-25( \pm 31) \%$, respectively (Figure 1, Table 2 ). Mean post-treatment $\mathrm{V}_{\mathrm{S}} / \mathrm{f}_{\mathrm{P}}$ values for the prefrontal cortex, brainstem, and cerebellum were 4.1, 7.2, and 5.5, respectively, which demonstrated movement toward $\mathrm{V}_{\mathrm{S}} / \mathrm{f}_{\mathrm{P}}$ values from non-smokers by 3.0, 5.5, and 4.1, respectively, from a separate study (Brody et al, 2013). Thus, treated smokers had $54.2,60.5$, and $60.0 \%$ normalization of nAChR levels for the three regions, respectively.

Participants who quit smoking had greater reductions in $\mathrm{V}_{\mathrm{S}} / \mathrm{f}_{\mathrm{P}}$ across regions than non-quitters (for prefrontal cortex, brainstem, and cerebellum: $-25,-38$, and $-42 \%$ for quitters and $-19,-21,-20 \%$ for non-quitters), respectively. Furthermore, correlations were found between reductions in cigarettes per day and decreases in $\mathrm{V}_{S} / \mathrm{f}_{\mathrm{P}}$ for two of the three ROIs studied $(r=0.33, P=0.02$ for the brainstem, $r=0.37, P=0.01$ for the cerebellum, and $r=0.18, P=0.22$ for the prefrontal cortex).

For completeness, a statistical analysis with the same general structure as above was performed for $V_{S} / f_{P}$ values for the thalamus (the region without significant smoking-induced upregulation of nAChRs). In this analysis, change in $\mathrm{V}_{\mathrm{S}} / \mathrm{f}_{\mathrm{P}}$ from pre- to post-treatment, difference between quitters and non-quitters with treatment, and effect of treatment type were not significant $(\mathrm{F}(1,41)=3.7, \mathrm{~F}(1,41)=0.1$, and $\mathrm{F}(2,41)=0.3$, respectively, all $P$-values NS).

Table I Demographics and Rating Scale Scores for Overall Study Sample $(n=48)$ and Subgroups Based on Treatment Type

\begin{tabular}{|c|c|c|c|c|}
\hline Variable & $\begin{array}{l}\text { Study sample } \\
\quad(n=48)\end{array}$ & $\begin{array}{c}\text { Cognitive-behavioral therapy } \\
\text { subgroup }(n=16)\end{array}$ & $\begin{array}{l}\text { Bupropion-treated } \\
\text { subgroup }(n=18)\end{array}$ & $\begin{array}{l}\text { Placebo-treated } \\
\text { subgroup }(n=14)\end{array}$ \\
\hline Age & $42.8( \pm 13.7)$ & $51.6( \pm 12.3)^{\mathrm{a}}$ & $35.5( \pm 11.6)$ & $42.1( \pm 12.5)$ \\
\hline Ethnicity (\% Caucasian) & 54.2 & 37.5 & 55.5 & 71.4 \\
\hline Education (years) & $14.5( \pm 1.9)$ & $14.4( \pm 2.5)$ & $14.3( \pm 1.4)$ & $14.9( \pm 2.0)$ \\
\hline Beck Depression Inventory & $1.8( \pm 2.0)$ & $2.1( \pm 2.6)$ & $1.5( \pm 1.5)$ & $2.0( \pm 2.6)$ \\
\hline Fagerström Test for Nicotine Dependence & $4.4( \pm 2.0)$ & $5.3( \pm 2.3)$ & $3.9( \pm 1.5)$ & $4.0( \pm 2.1)$ \\
\hline Quit attempts lifetime & $2.7( \pm 2.5)$ & $2.9( \pm 2.4)$ & $2.2( \pm 2.3)$ & $3.1( \pm 2.9)$ \\
\hline Cigarettes per day pre-treatment & $19.6( \pm 4.0)$ & $20.4( \pm 4.5)$ & $18.7( \pm 4.2)$ & $19.9( \pm 3.1)$ \\
\hline Cigarettes per day post-treatment & $9.2( \pm 8.0)^{b}$ & $5.4( \pm 6.8)^{c}$ & $12.0( \pm 7.7)$ & $10.0( \pm 8.5)$ \\
\hline Percentage of change in exhaled $\mathrm{CO}$ with treatment & $-51.0( \pm 39.1)$ & $-59.3( \pm 39.6)$ & $-50.7( \pm 40.7)$ & $-42.1( \pm 37.2)$ \\
\hline
\end{tabular}

All values are presented as mean $( \pm \mathrm{SD})$ or percentages.

${ }^{a} P<0.0$ l between subgroups (ANOVA).

${ }^{\mathrm{b}} P=0.00 \mathrm{I}$ for change in cigarettes per day for the study sample from pre- to post-treatment.

${ }^{c} P<0.01$ for the between-subgroups change in cigarettes per day from pre- to post-treatment.

$\mathrm{d} P<0.05$ for change in exhaled carbon monoxide (CO) from pre- to post-treatment for the study sample. 
Table 2 Specific Binding Volumes of Distribution $\left(V_{S} / f_{P}\right)$ in Brain Regions of Interest Pre- and Post-Treatment

\begin{tabular}{|c|c|c|c|c|}
\hline Brain region & $\begin{array}{c}V_{\mathbf{s}} / f_{\mathrm{P}} \text { values_smoker } \\
\text { group }(n=48)\end{array}$ & $\begin{array}{c}V_{S} / f_{P} \text { values-CBT-treated } \\
\text { smokers }(n=14)\end{array}$ & $\begin{array}{c}\mathbf{V}_{\mathbf{S}} / \mathrm{f}_{\mathrm{P}} \text { values_bupropion-treated } \\
\text { smokers }(n=18)\end{array}$ & $\begin{array}{c}\mathbf{V}_{\mathbf{S}} / f_{\mathbf{P}} \text { values-placebo-treated } \\
\text { smokers }(n=16)\end{array}$ \\
\hline $\begin{array}{l}\text { Pre-treatment } \\
\text { prefrontal cortex }\end{array}$ & $5.4( \pm 2.3)$ & $5.8( \pm 2.0)$ & $5.3( \pm 3.0)$ & $5.2( \pm 1.6)$ \\
\hline $\begin{array}{l}\text { Post-treatment } \\
\text { prefrontal cortex }\end{array}$ & $4.1( \pm 1.8)$ & $4.0( \pm 1.7)$ & $4.0( \pm 2.0)$ & $4.3( \pm 1.8)$ \\
\hline $\begin{array}{l}\text { Percentage of } \Delta \\
\text { prefrontal cortex }\end{array}$ & $-20( \pm 36)^{*}$ & $-28( \pm 28)$ & $-18( \pm 40)$ & $-15( \pm 39)$ \\
\hline $\begin{array}{l}\text { Post-treatment } \\
\text { brainstem }\end{array}$ & $7.2( \pm 2.9)$ & $6.8( \pm 2.0)$ & $7.6( \pm 3.1)$ & $7.1( \pm 3.7)$ \\
\hline $\begin{array}{l}\text { Percentage of } \Delta \\
\text { brainstem }\end{array}$ & $-25( \pm 26)^{* * *}$ & $-32( \pm 22)$ & $-19( \pm 22)$ & $-25( \pm 35)$ \\
\hline $\begin{array}{l}\text { Percentage of } \Delta \\
\text { cerebellum }\end{array}$ & $-25( \pm 31)$ & $-33( \pm 25)$ & $-21( \pm 26)$ & $-21( \pm 42)$ \\
\hline
\end{tabular}

All values are mean $\pm S D ; * P \leqslant 0.05, * * P \leqslant 0.01$, repeated-measures analyses of covariance for the study sample from pre- to post-treatment with $V_{S} / f_{P}$ for the brain regions as the repeated measures, treatment group and quit status as between-subject factors, and age as a covariate.

${ }^{a} P \leqslant 0.05$ for cerebellar $V_{S} / f_{P}$ value differences before treatment between CBT-treated and placebo-treated smokers (uncorrected). No other between-group differences were significant.

\section{Associations between nAChR Densities and Subjective Symptoms: Exploratory Analyses}

Correlations were found between change in pre- to posttreatment $\mathrm{V}_{\mathrm{S}} / \mathrm{f}_{\mathrm{P}}$ values and change in ratings of smokingrelated reward for the prefrontal cortex $(r=0.30, P<0.05)$, brainstem $(r=0.44, P<0.01)$, and cerebellum $(r=0.39$, $P<0.01)$, indicating that diminished $\mathrm{nAChR}$ density was associated with a decreased subjective sense of the rewarding properties of smoking. Similarly, $\mathrm{V}_{\mathrm{S}} / \mathrm{f}_{\mathrm{P}}$ values and ratings of cigarette taste were correlated for the brainstem $(r=0.28, P=0.05)$, with similar (but nonsignificant) directional associations for the prefrontal cortex $(r=0.18, \mathrm{NS})$ and cerebellum $(r=0.26, P=0.08)$. Associations between nAChR density and UTS craving scores were not significant ( $r$ 's ranged from -0.19 to -0.11 ).

For the POMS, negative correlations were found between changes in $V_{S} / f_{P}$ values and anger/hostility for the prefrontal cortex $(r=-0.38, \quad P<0.01)$, brainstem $(r=-0.41, \quad P<0.005), \quad$ and cerebellum $(r=-0.32$, $\mathrm{P}<0.05$ ), indicating that greater reduction in $\mathrm{nAChR}$ densities was associated with increased levels of anger/ hostility. No other correlations between $\mathrm{V}_{\mathrm{S}} / \mathrm{f}_{\mathrm{P}}$ values and other subscales on the POMS or SJWS were found.

\section{Associations between Pre-Treatment Variables and Quit Status: Exploratory Analyses}

As expected, smoking fewer cigarettes per day at baseline was associated with a greater likelihood of quitting (Table 3). Similarly, there were statistical trends for lower pre-treatment cigarette-related symptoms (FTND, UTS craving scale, SJWS craving subscale, SJWS physical symptom subscale, and ratings of taste and reward) to be
Table 3 Pre-Treatment Predictors of Quitting Smoking (Binary Logistic Regression Analyses)

\begin{tabular}{lcccc}
\hline $\begin{array}{l}\text { Pre-treatment } \\
\text { variable }\end{array}$ & $\begin{array}{c}\text { Quitters } \\
\text { (mean } \pm \text { SD) }\end{array}$ & $\begin{array}{c}\text { Non-quitters } \\
\text { (mean } \pm \text { SD) }\end{array}$ & $\chi^{2}$ & P-value \\
\hline Cigarettes/day & $17.8 \pm 3.1$ & $20.3 \pm 4.0$ & 4.8 & 0.03 \\
FTND & $4.3 \pm 1.7$ & $5.3 \pm 2.9$ & 2.3 & 0.13 \\
UTS craving scale & $2.7 \pm 1.5$ & $3.4 \pm 1.6$ & 2.4 & 0.12 \\
score & $31.3 \pm 12.7$ & $37.6 \pm 10.8$ & 2.7 & 0.09 \\
SJWS craving & $18.1 \pm 8.5$ & $17.4 \pm 7.6$ & 0.1 & 0.77 \\
SJWS psychological & & & & \\
distress & $8.4 \pm 4.7$ & $6.4 \pm 3.1$ & 3.1 & 0.08 \\
SJWS physical & $10.0 \pm 4.8$ & $10.5 \pm 5.3$ & 0.1 & 0.75 \\
symptoms & $9.3 \pm 3.0$ & $8.6 \pm 2.8$ & 0.6 & 0.46 \\
SJWS stimulation & $5.4 \pm 2.3$ & $6.7 \pm 2.3$ & 3.0 & 0.08 \\
SJWS appetite & $6.2 \pm 2.2$ & $7.2 \pm 1.9$ & 2.6 & 0.10 \\
Taste of a cigarette & $4.8 \pm 2.0$ & $5.8 \pm 2.4$ & 2.0 & 0.16 \\
Reward of a cigarette & & & & \\
Prefrontal cortex $V_{S} /$ & $8.5 \pm 2.7$ & $10.5 \pm 3.7$ & 3.5 & 0.06 \\
f $_{P}$ & $6.7 \pm 2.2$ & $8.0 \pm 2.9$ & 2.4 & 0.12 \\
Brainstem $V_{S} / f_{P}$ & Cerebellum $V_{S} / f_{P}$ & & & \\
\hline
\end{tabular}

Abbreviations: FTND, Fagerström Test for Nicotine Dependence; UTS, Urge to Smoke; $V_{S} / f_{P}$, specific binding volume of distribution.

associated with a better chance of quitting. Associations between pre-treatment $V_{S} / f_{P}$ values and quit status did not reach significance, but results gave trend-level indications that lower $\mathrm{nAChR}$ density in all three brain regions 
(prefrontal cortex, brainstem, and cerebellum) were associated with a greater likelihood of quitting.

\section{DISCUSSION}

Smoking reduction and cessation with commonly used treatments led to decreases in $\alpha_{4} \beta_{2}{ }^{*} \mathrm{nAChR}$ densities across brain regions. These reductions moved smokers toward normal $\alpha_{4} \beta_{2}{ }^{*}$ nAChR levels found in non-smokers. No associations between $\alpha_{4} \beta_{2}{ }^{*} \mathrm{nAChR}$ densities and treatment type were found, but significant associations were discovered between the extent of $\alpha_{4} \beta_{2}{ }^{*}$ nAChR density reduction and the amount of decreased cigarette usage. These results indicate that $\alpha_{4} \beta_{2}{ }^{*} \mathrm{nAChR}$ density is strongly linked to the number of cigarettes smoked per day, but not to the treatment type being administered, and are consistent with our previous study of untreated smokers (Brody et al, 2013) and other studies linking nicotine (Marks et al, 2011; Yates et al, 1995; Zhang et al, 2002) and cigarette smoke (Mamede et al, 2007; Mukhin et al, 2008; Staley et al, 2006; Wullner et al, 2008) exposure with upregulation of $\alpha_{4} \beta_{2}{ }^{*}$ nAChRs in brain regions other than the thalamus. Because education about the biological effects of smoking and quitting smoking are standard parts of smoking-cessation psychotherapy (Fiore et al, 2008), the additional information found here could prove useful in treatment of smokers by letting them know that brain receptor changes found with regular smoking tend toward normalization with smoking reduction and cessation.

In the exploratory analyses, decreases in $\alpha_{4} \beta_{2}{ }^{*} \mathrm{nAChR}$ levels with treatment were associated with decreases in the perceived rewarding properties and taste of cigarettes, along with increased anger/hostility. The findings with reward/ taste are strongly supported by studies of laboratory animals in which $\alpha_{4} \beta_{2}{ }^{*}$ nAChR agonism has been linked with the rewarding properties of nicotine (McGranahan et al, 2011), while $\alpha_{4} \beta_{2}{ }^{*}$ nAChR antagonism has been found to block nicotine's rewarding properties (Tobey et al, 2012; Walters et al, 2006). Similarly, a study of $\alpha_{4}$ mutant knockout mice found that these mice did not have nicotine-elicited increases in dopamine levels (Marubio et al, 2003), which is highly consistent with our finding that decreases in $\alpha_{4} \beta_{2}{ }^{*} \mathrm{nAChR}$ levels were associated with diminished reward from cigarettes (presumably mediated at least in part through dopamine release). Additionally, it is noted that nicotine replacement therapy (commonly used for smoking cessation treatment) decreases the rewarding properties of smoking (Levin et al, 1994) and would be expected to maintain upregulation of $\alpha_{4} \beta_{2}{ }^{*}$ nAChRs. Taken together, these findings indicate that the rewarding property of smoking and perceived taste of cigarettes are related to the number of available $\alpha_{4} \beta_{2}{ }^{*}$ nAChRs, though the exact nature of the relationship between these symptoms and $\alpha_{4} \beta_{2}{ }^{*} \mathrm{nAChR}$ density remains to be verified. As for anger/ hostility, we are not aware of studies specifically linking $\mathrm{nAChR}$ density with this state; therefore, this finding may represent an epiphenomenon and needs verification by prospective work focusing on this variable.

For the exploratory analyses of pre-treatment predictors of quitting smoking, a lower number of cigarettes per day was associated with a greater likelihood of quitting, which is consistent with previous research (Batra et al, 2008; Dale et al, 2001; Hymowitz et al, 1997; Japuntich et al, 2011; Kozlowski et al, 1994; Paluck et al, 2006; Westman et al, 1997). Interestingly, a number of other measures (including brain nAChR levels) that could be thought of as being associated with severity of nicotine dependence had trendlevel associations with treatment outcome. Although not reaching significance, FTND scores, craving/withdrawal scores, and reward/taste scores were lower at baseline in those smokers who quit with treatment compared with those who did not quit. Similarly, smokers with lower baseline nAChR densities (presumably the result of less severe $\mathrm{nAChR}$ upregulation) showed a trend toward being more likely to quit. The prediction of treatment response with pre-treatment nAChR densities is highly consistent with pharmacogenetic studies, which found associations between response to first-line medications for smoking cessation and genetic variability in neuroreceptors (nAChRs and DRD1 receptors) and nicotine metabolism (Bergen et al, 2013; King et al, 2012; Lee et al, 2012).

A central limitation of the study was sample size. Although this study was relatively large for a PET study of this type (with 110 PET scanning sessions being analyzed), natural variability in treatment response within this small sample likely resulted in the relatively high response rate with pill placebo compared with bupropion (and the unexpectedly high quit rate with $\mathrm{CBT}$ ). Furthermore, the trend-level findings in several of the exploratory analyses indicate that a larger sample size might provide an enhanced ability to differentiate responses to active $v s$ placebo treatment and to elucidate the extent to which nAChR levels can be used to predict treatment response. A larger sample size would also allow for greater power to determine nAChR differences based on sex, as has been reported previously in smokers (Cosgrove et al, 2012). Additionally, it should be noted that bupropion $\mathrm{HCl}$ acts as a noncompetitive nAChR antagonist (Slemmer et al, 2000), which may have affected radiotracer binding or $\mathrm{nAChR}$ normalization, though the absence of between-group differences in normalization indicates against a specific effect of bupropion.

In summary, this PET study demonstrated movement toward normalization of $\mathrm{nAChR}$ upregulation with standard treatments for smoking. This diminished upregulation was strongly correlated with decreases in smoking levels. Exploratory analyses indicated that decreases in $\mathrm{nAChR}$ densities were associated with diminished taste/reward of smoking a cigarette and increased anger/hostility and that pre-treatment clinical and brain imaging findings may result in the ability to predict who will respond to treatment.

\section{ACKNOWLEDGEMENTS}

This study was supported by the National Institute on Drug Abuse (ALB (R01 DA20872)), the Tobacco-Related Disease Research Program (ALB (19XT-0135)), and the Department of Veterans Affairs, Office of Research and Development (CSR\&D Merit Review Award I01 CX000412 (ALB)). The sponsors had no role in the design and conduct of the study; collection, management, analysis, and interpretation of the data; or preparation, review, or approval of the manuscript. 


\section{DISCLOSURE}

ALB and MAM were previously co-investigators on a grant funded by Pfizer, Inc. that was unrelated to this study. AGM is a co-investigator on a grant from Phillip Morris, Inc. for research unrelated to this study. All the other authors report no biomedical financial disclosures or potential conflicts of interest.

\section{REFERENCES}

Abrams DB, Niaura RS, Brown RA, Emmons KM, Goldstein MG, Monti PM (2003). The Tobacco Dependence Treatment Handbook: A Guide to Best Practices. The Guilford Press: New York.

Agboola S, McNeill A, Coleman T, Leonardi Bee J (2010). A systematic review of the effectiveness of smoking relapse prevention interventions for abstinent smokers. Addiction 105: 1362-1380.

Al'Absi M, Carr SB, Bongard S (2007). Anger and psychobiological changes during smoking abstinence and in response to acute stress: prediction of smoking relapse. Int J Psychophysiol 66: 109-115.

Batra A, Collins SE, Torchalla I, Schroter M, Buchkremer G (2008). Multidimensional smoker profiles and their prediction of smoking following a pharmacobehavioral intervention. J Subst Abuse Treat 35: 41-52.

Beck A, Steer R (1996). Manual for BDI-II. Psychological Corporation: San Antonio, TX, USA.

Benwell ME, Balfour DJK, Anderson JM (1988). Evidence that tobacco smoking increases the density of (-)-[3H]nicotine binding sites in human brain. J Neurochem 50: 1243-1247.

Bergen AW, Javitz HS, Krasnow R, Nishita D, Michel M, Conti DV et al (2013). Nicotinic acetylcholine receptor variation and response to smoking cessation therapies. Pharmacogenet Genomics 23: 94-103.

Breese CR, Marks MJ, Logel J, Adams CE, Sullivan B, Collins AC et al (1997). Effect of smoking history on [3H]nicotine binding in human postmortem brain. J Pharmacol Exp Ther 282: 7-13.

Brody AL, Mandelkern MA, Costello MR, Abrams AL, Scheibal D, Farahi J et al (2009). Brain nicotinic acetylcholine receptor occupancy: effect of smoking a denicotinized cigarette. Int $J$ Neuropsychopharmacol 12: 305-316.

Brody AL, Mandelkern MA, London ED, Khan A, Kozman D, Costello MR et al (2011). Effect of secondhand smoke on occupancy of nicotinic acetylcholine receptors in brain. Arch Gen Psychiatry 68: 953-960.

Brody AL, Mandelkern MA, London ED, Olmstead RE, Farahi J, Scheibal D et al (2006). Cigarette smoking saturates brain alpha4beta2 nicotinic acetylcholine receptors. Arch Gen Psychiatry 63: 907-915.

Brody AL, Mukhin AG, La Charite J, Ta K, Farahi J, Sugar CA et al (2013). Up-regulation of nicotinic acetylcholine receptors in menthol cigarette smokers. Int J Neuropsychopharmacol (e-pub ahead of print).

Cahill K, Stead LF, Lancaster T (2011). Nicotine receptor partial agonists for smoking cessation. Cochrane Database Syst Rev 2: CD006103.

Carmody TP (1990). Preventing relapse in the treatment of nicotine addiction: current issues and future directions. J Psychoactive Drugs 22: 211-238.

CDC (2009). Cigarette smoking among adults and trends in smoking cessation-United States 2008. MMWR Morb Mortal Wkly Rep 58: 1227-1232.

Cosgrove KP, Batis J, Bois F, Maciejewski PK, Esterlis I, Kloczynski $\mathrm{T}$ et al (2009). beta2-Nicotinic acetylcholine receptor availability during acute and prolonged abstinence from tobacco smoking. Arch Gen Psychiatry 66: 666-676.
Cosgrove KP, Esterlis I, McKee SA, Bois F, Seibyl JP, Mazure CM et al (2012). Sex differences in availability of beta $2^{\star}$-nicotinic acetylcholine receptors in recently abstinent tobacco smokers. Arch Gen Psychiatry 69: 418-427.

Dale LC, Glover ED, Sachs DP, Schroeder DR, Offord KP, Croghan IT et al (2001). Bupropion for smoking cessation: predictors of successful outcome. Chest 119: 1357-1364.

Dolle F, Valette H, Bottlaender M, Hinnen F, Vaufrey F, Guenther I et al (1998). Synthesis of 2-[F-18]fluoro-3-[2(S)-2-azetidinylmethoxy]pyridine, a highly potent radioligand for in vivo imaging central nicotinic acetylcholine receptors. J Labelled Compounds Radiopharm 41: 451-463.

Fant RV, Buchhalter AR, Buchman AC, Henningfield JE (2009). Pharmacotherapy for tobacco dependence. Handbook Exp Pharmacol 192: 487-510.

Fiore MC, Bailey WC, Cohen SJ, Dorfman SF, Goldstein MG, Gritz ER et al (2000). Treating Tobacco Use and Dependence. Clinical Practice Guideline. U.S. Department of Health and Human Services. Public Health Service: Rockville, MD, USA.

Fiore MC, Jaen CR, Baker TB (2008). Treating Tobacco Use and Dependence: 2008 Update. Department of Health and Human Services: Rockville, MD, USA.

Govind AP, Vezina P, Green WN (2009). Nicotine-induced upregulation of nicotinic receptors: underlying mechanisms and relevance to nicotine addiction. Biochem Pharmacol 78: 756-765.

Gwaltney CJ, Shiffman S, Balabanis MH, Paty JA (2005). Dynamic self-efficacy and outcome expectancies: prediction of smoking lapse and relapse. J Abnorm Psychol 114: 661-675.

Haaga DA, Stewart BL (1992). Self-efficacy for recovery from a lapse after smoking cessation. J Consult Clin Psychol 60: 24-28.

Hamilton M (1967). Development of a rating scale for primary depressive illness. Br J Soc Psychol 6: 278-296.

Hamilton M (1969). Diagnosis and rating of anxiety. $\mathrm{Br} J$ Psychiatry 3: 76-79.

Heatherton TF, Kozlowski LT, Frecker RC, Fagerstrom KO (1991). The Fagerstrom Test for Nicotine Dependence: a revision of the Fagerstrom Tolerance Questionnaire. Br J Addict 86: 1119-1127.

Hughes JR, Keely JP, Niaura RS, Ossip-Klein DJ, Richmond RL, Swan GE (2003). Measures of abstinence in clinical trials: issues and recommendations. Nicotine Tob Res 5: 13-25.

Hymowitz N, Cummings KM, Hyland A, Lynn WR, Pechacek TF, Hartwell TD (1997). Predictors of smoking cessation in a cohort of adult smokers followed for five years. Tob Control 6(Suppl 2): S57-S62.

Innis RB, Cunningham VJ, Delforge J, Fujita M, Gjedde A, Gunn $\mathrm{RN}$ et al (2007). Consensus nomenclature for in vivo imaging of reversibly binding radioligands. J Cereb Blood Flow Metab 27: 1533-1539.

Jamal A, Dube SR, Malarcher AM, Shaw L, Engstrom MC (2012). Tobacco use screening and counseling during physician office visits among adults - National Ambulatory Medical Care Survey and National Health Interview Survey, United States, 2005-2009. MMWR Morb Mortal Wkly Rep 61(Suppl): 38-45.

Japuntich SJ, Leventhal AM, Piper ME, Bolt DM, Roberts LJ, Fiore MC et al (2011). Smoker characteristics and smoking-cessation milestones. Am J Prev Med 40: 286-294.

Japuntich SJ, Smith SS, Jorenby DE, Piper ME, Fiore MC, Baker TB (2007). Depression predicts smoking early but not late in a quit attempt. Nicotine Tob Res 9: 677-686.

Jarvik ME, Madsen DC, Olmstead RE, Iwamoto-Schaap PN, Elins JL, Benowitz NL (2000). Nicotine blood levels and subjective craving for cigarettes. Pharmacol Biochem Behav 66: 553-558.

Kenford SL, Fiore MC, Jorenby DE, Smith SS, Wetter D, Baker TB (1994). Predicting smoking cessation. Who will quit with and without the nicotine patch. JAMA 271: 589-594.

Kimes AS, Chefer SI, Matochik JA, Contoreggi CS, Vaupel DB, Stein EA et al (2008). Quantification of nicotinic acetylcholine 
receptors in the human brain with PET: bolus plus infusion administration of 2-[18F]F-A85380. Neuroimage 39: 717-727.

King DP, Paciga S, Pickering E, Benowitz NL, Bierut LJ, Conti DV et al (2012). Smoking cessation pharmacogenetics: analysis of varenicline and bupropion in placebo-controlled clinical trials. Neuropsychopharmacology 37: 641-650.

Kozlowski LT, Porter CQ, Orleans CT, Pope MA, Heatherton T (1994). Predicting smoking cessation with self-reported measures of nicotine dependence: FTQ, FTND, and HSI. Drug Alcohol Depend 34: 211-216.

Lee W, Ray R, Bergen AW, Swan GE, Thomas P, Tyndale RF et al (2012). DRD1 associations with smoking abstinence across slow and normal nicotine metabolizers. Pharmacogenet Genomics 22: 551-554.

Lester HA, Xiao C, Srinivasan R, Son CD, Miwa J, Pantoja R et al (2009). Nicotine is a selective pharmacological chaperone of acetylcholine receptor number and stoichiometry. Implications for drug discovery. Am Assoc Pharm Scientists J 11: 167-177.

Levin ED, Westman EC, Stein RM, Carnahan E, Sanchez M, Herman $S$ et al (1994). Nicotine skin patch treatment increases abstinence, decreases withdrawal symptoms, and attenuates rewarding effects of smoking. J Clin Psychopharmacol 14: 41-49.

Li WW, Froelicher ES (2008). Predictors of smoking relapse in women with cardiovascular disease in a 30-month study: extended analysis. Heart Lung 37: 455-465.

Mamede M, Ishizu K, Ueda M, Mukai T, Iida Y, Kawashima H et al (2007). Temporal change in human nicotinic acetylcholine receptor after smoking cessation: 5IA SPECT study. J Nucl Med 48: 1829-1835.

Marks MJ, McClure-Begley TD, Whiteaker P, Salminen O, Brown RW, Cooper J et al (2011). Increased nicotinic acetylcholine receptor protein underlies chronic nicotine-induced up-regulation of nicotinic agonist binding sites in mouse brain. $J$ Pharmacol Exp Ther 337: 187-200.

Marubio LM, Gardier AM, Durier S, David D, Klink R, ArroyoJimenez MM et al (2003). Effects of nicotine in the dopaminergic system of mice lacking the alpha4 subunit of neuronal nicotinic acetylcholine receptors. Eur J Neurosci 17: 1329-1337.

McGranahan TM, Patzlaff NE, Grady SR, Heinemann SF, Booker TK (2011). alpha4beta2 nicotinic acetylcholine receptors on dopaminergic neurons mediate nicotine reward and anxiety relief. J Neurosci 31: 10891-10902.

McNair DM, Lorr D, Droppelman LF (1988). Manual for the Profile of Mood States. Educational Testing Services: San Diego, CA, USA.

Mitsis EM, Cosgrove KP, Staley JK, Frohlich EB, Bois F, Tamagnan GD et al (2007). [123I]5-IA-85380 SPECT imaging of beta2nicotinic acetylcholine receptor availability in the aging human brain. Ann N Y Acad Sci 1097: 168-170.

Mukhin AG, Kimes AS, Chefer SI, Matochik JA, Contoreggi CS, Horti AG et al (2008). Greater nicotinic acetylcholine receptor density in smokers than in nonsmokers: a PET study with $2-18 \mathrm{~F}-$ FA-85380. J Nucl Med 49: 1628-1635.

Paluck EC, McCormack JP, Ensom MH, Levine M, Soon JA, Fielding DW (2006). Outcomes of bupropion therapy for smoking cessation during routine clinical use. Ann Pharmacother 40: 185-190.

Quick MW, Lester RA (2002). Desensitization of neuronal nicotinic receptors. J Neurobiol 53: 457-478.

Rigotti NA, Gonzales D, Dale LC, Lawrence D, Chang Y (2009). A randomized controlled trial of adding the nicotine patch to rimonabant for smoking cessation: efficacy, safety and weight gain. Addiction 104: 266-276.

Rogers SW, Gahring LC, Collins AC, Marks M (1998). Age-related changes in neuronal nicotinic acetylcholine receptor subunit $\alpha 4$ expression are modified by long-term nicotine administration. $J$ Neurosci 18: 4825-4832.

Schnoll RA, James C, Malstrom M, Rothman RL, Wang H, Babb J et al (2003). Longitudinal predictors of continued tobacco use among patients diagnosed with cancer. Ann Behav Med 25: 214-222.

Schnoll RA, Patterson F, Wileyto EP, Tyndale RF, Benowitz N, Lerman C (2009). Nicotine metabolic rate predicts successful smoking cessation with transdermal nicotine: a validation study. Pharmacol Biochem Behav 92: 6-11.

Shiffman S, Balabanis MH, Gwaltney CJ, Paty JA, Gnys M, Kassel JD et al (2007). Prediction of lapse from associations between smoking and situational antecedents assessed by ecological momentary assessment. Drug Alcohol Depend 91: 159-168.

Shiffman S, Balabanis MH, Paty JA, Engberg J, Gwaltney CJ, Liu KS et al (2000). Dynamic effects of self-efficacy on smoking lapse and relapse. Health Psychol 19: 315-323.

Shiffman SM, Jarvik ME (1976). Smoking Withdrawal Symptoms in Two Weeks of Abstinence. Psychopharmacology (Berl) 50: 35-39.

Slemmer JE, Martin BR, Damaj MI (2000). Bupropion is a nicotinic antagonist. J Pharmacol Exp Ther 295: 321-327.

Staley JK, Krishnan-Sarin S, Cosgrove KP, Krantzler E, Frohlich E, Perry E et al (2006). Human tobacco smokers in early abstinence have higher levels of beta $2^{*}$ nicotinic acetylcholine receptors than nonsmokers. J Neurosci 26: 8707-8714.

Tobey KM, Walentiny DM, Wiley JL, Carroll FI, Damaj MI, Azar MR et al (2012). Effects of the specific alpha4beta2 nAChR antagonist, 2-fluoro-3-(4-nitrophenyl) deschloroepibatidine, on nicotine reward-related behaviors in rats and mice. Psychopharmacology (Berl) 223: 159-168.

Walters CL, Brown S, Changeux JP, Martin B, Damaj MI (2006). The beta2 but not alpha7 subunit of the nicotinic acetylcholine receptor is required for nicotine-conditioned place preference in mice. Psychopharmacology (Berl) 184: 339-344.

Waters AJ, Shiffman S, Sayette MA, Paty JA, Gwaltney CJ, Balabanis MH (2004). Cue-provoked craving and nicotine replacement therapy in smoking cessation. J Consult Clin Psychol 72: 1136-1143.

West R, Hajek P, Stead L, Stapleton J (2005). Outcome criteria in smoking cessation trials: proposal for a common standard. Addiction 100: 299-303.

Westman EC, Behm FM, Simel DL, Rose JE (1997). Smoking behavior on the first day of a quit attempt predicts long-term abstinence. Arch Intern Med 157: 335-340.

Whiting PJ, Lindstrom JM (1988). Characterization of bovine and human neuronal nicotinic acetylcholine receptors using monoclonal antibodies. J Neurosci 8: 3395-3404.

Wiggers LC, Stalmeier PF, Oort FJ, Smets EM, Legemate DA, de Haes JC (2005). Do patients' preferences predict smoking cessation? Prev Med 41: 667-675.

Wullner U, Gundisch D, Herzog H, Minnerop M, Joe A, Warnecke $M$ et al (2008). Smoking upregulates alpha4beta $2^{*}$ nicotinic acetylcholine receptors in the human brain. Neurosci Lett 430: 34-37.

Yates SL, Bencherif M, Fluhler EN, Lippiello PM (1995). Upregulation of nicotinic acetylcholine receptors following chronic exposure of rats to mainstream cigarette smoke or alpha 4 beta 2 receptors to nicotine. Biochem Pharmacol 50: 2001-2008.

Zhang X, Tian JY, Svensson AL, Gong ZH, Meyerson B, Nordberg A (2002). Chronic treatments with tacrine and (-)-nicotine induce different changes of nicotinic and muscarinic acetylcholine receptors in the brain of aged rat. J Neural Transm 109: 377-392. 